\title{
Management of Chronic Kidney Disease- an Update
}

\author{
F Ahammad
}

\begin{abstract}
:
Chronic kidney disease (CKD) is a global public health issue demanding continuous improvement in its management. Different international groups and organizations have now achieved a good progress in its definition, classification (staging), treatment and referral criteria to nephrologists. In definition of CKD, "CKD is defined as abnormalities of kidney structure or function, present for at least three months with implications for health", the phrase "with implications for health" has been added at the end of the previous definition, which reflects the concept that there may be certain abnormalities of kidney structure or function that do not have prognostic consequences (for example, a simple renal cyst). At staging of CKD, grade 3 has been subdivided into G3a and G3b, according to whether the glomerular filtration rate (GFR) is $(59-45)$ or $(44-30) \mathrm{ml} / \mathrm{min} / 1.73 \mathrm{~m}^{2}$, respectively. Furthermore, albuminuria has been classified in any GFR grade, in to A1, A2 or A3 according to the albumin-creatinine ratio (ACR) in an isolated urine sample for values $<3,3-30$ or $>30 \mathrm{mg} / \mathrm{mmol}$, respectively. The term "microalbuminuria" has now been replaced by the term "moderately increased albuminuria". For GFR measurement Chronic Kidney Disease Epidemiology Collaboration (CKD- EPI) equation has been preferred than the Modification of Diet in Renal Disease (MDRD) study equation and new 2012 KDIGO guidelines consider the use of alternative formulas to be acceptable if they have been shown to improve accuracy when compared with the CKD-EPI formula. For detection of albuminuria ACR is preferred rather than conventional 24 hours urine albumin. The recommended BP control target is $\leq 140 / 90 \mathrm{mmHg}$ (both diabetic and non-diabetic) if ACR $<3 \mathrm{mg} / \mathrm{mmol}$ and a stricter target is suggested, with BP $\leq 130 / 80 \mathrm{mmHg}$, (both in diabetic and non-diabetic) if the ACR is $\geq 3 \mathrm{mg} / \mathrm{mmol}$. Use of erythropoisis-stimulating agent (ESA) in anemia of CKD should be rational; to avoid its adverse effects like stroke, thrombosis or hypertension acceleration and hemoglobin goals should not exceed $11 \mathrm{~g}$ per dl. Treating dyslipidaemia in CKD with statins for all adults $>50$ years of age, irrespective of low density lipoprotien (LDL) cholesterol levels is recommended. Referral to nephrologist should be rational according to guidelines and at least one year prior to the start of renal replacement therapy (RRT).
\end{abstract}

Key words : CKD, ACR, GFR.

\section{Introduction :}

More than 35 million people in the United States (US) are currently affected by $\mathrm{CKD}^{1}$. The prevalence is risingand it is estimated that by 2030 , more than 2 million people in the US will need dialysis or transplantation for kidney failure. Epidemiological view of chronic kidney disease has experienced a significant change in the last twenty years. Initially CKD was restricted to relatively low incidence pathologies, such as glomerular diseases or hereditary nephropathies, and to a specialized care setting (Nephrology unit), but now a days the disease is related to highly prevalent diseases or phenomena, such as old age, high BP, diabetes or

1. Dr. FarukAhammad, MBBS, FCPS (Medicine), Associate Professor, Department of medicine, Faridpur Medical College, Faridpur.

Address of correspondence :

Dr. FarukAhammad. MBBS, FCPS (Medicine), Associate Professor, Department of medicine, Faridpur Medical College, Faridpur. Phone:+88-01817011894. Email:farukahammad26@yahoo.com cardiovascular disease and is being treated often as a co morbidity by many medical specialties, particularly Primary Care, Internal Medicine, Cardiology, Geriatrics, Endocrinology and any other medical or surgical specialty, especially those related to old age. Advanced CKD patients included in RRT programme using dialysis and transplantation are considered the visible part of the iceberg. Since evidence has shown that treatment at earlier stages is generally effective in preventing or delaying adverse outcomes, management of patients with and at risk of CKD becomes critically important for decreasing morbidity and mortality. The aim of this article is to provide updated information about diagnosis, management and treatment, to assess prognosis of CKD patients and criteria for referral to the nephrologist. Management of end stage renal failure (ESRF), RRT; dialysis and renal transplantation which are dealt in special renal unit, are not considered here. 


\section{Materials and Methods :}

Pub Med was searched in July 2014 for all English language publications including the search terms "chronic kidney disease", "Definition and grades of CKD", "Update management of CKD," " International guidelines for CKD" from January 2000 onwards. The full articles of selected identified records that were thought to be potentially relevant were collected. The references in these articles were also checked for additional relevant information.

\section{Definition of CKD :}

CKD is defined as abnormalities of kidney structure or function, present for at least three months with implications for health ${ }^{2,3}$.

Chronic kidney disease (CKD) is diagnosed as:

* an estimated or measured glomerular filtration rate (GFR) $<60 \mathrm{~mL} / \mathrm{min} / 1.73 \mathrm{~m}^{2}$ that is present for $\geq 3$ months with or without evidence of kidney damage.

or

* evidence of kidney damage with or without decreased GFR that is present fo $\geq 3$ months as evidenced by the following, irrespective of the underlying cause:

- albuminuria (ACR=3mg/mmol or more; AER (albumin excretion rate) $=30 \mathrm{mg}$ or more $/ 24 \mathrm{hrs}$ )

- haematuria or leucocyturia after exclusion of urological causes

- Electrolyte and other abnormalities due to tubular disorders

- Structural abnormalities detected by histology

- Structural abnormalities detected by imaging

- History of Kidney transplantation

The duration (three months) for any of these abnormalities is confirmed prospectively or deduced from previous registries. In newly diagnosed CKD patients, GFR estimation must be repeated within a period of no less than three months, to exclude acute renal deterioration due to diarrhea, vomiting, use of diuretics or any drug that affects glomerular haemodynamics, such as angiotensin converting enzyme inhibitors (ACEI) or angiotensin receptor blockers (ARB).

\section{Measurement of GFR :}

GFR has traditionally been estimated using the 24-hour creatinine clearance; however, a calculation of estimated glomerular filtration rate (eGFR) is now recommended. The eGFR, based on serum creatinine and/or cystatin $\mathrm{C}$, is a simpler and generally more reliable test. The new guidelines recommend for estimating GFR using isotope dilution mass spectrometry (IDMS)-traceable serum creatinine measurements and the patient's age (18 years and older), gender, and race (African American vs non-African American) according to the CKD-EPI equation ${ }^{4}$.

\section{CKD-EPIequation}

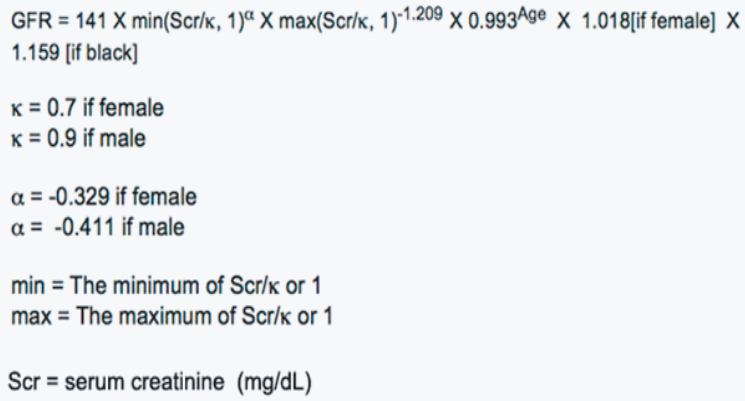

Recently the MDRD study equation has been replaced by CKD-EPI equation for GFR measurement ${ }^{5}$ and new 2012 KDIGO guidelines consider the use of alternative formulas to be acceptable if they have been shown to improve accuracy when compared with the CKD-EPI formula.

MDRD equation:

$$
\begin{gathered}
\text { eGFR } \left.=186 \times(\text { creatinine })-^{1.154} \times(\text { age })^{-0.203} \times 0.742 \text { (if female }\right) \times \\
1.21 \text { (if black) }
\end{gathered}
$$

The values obtained using the MDRD or CKD-EPI equations are adjusted for a body surface area (BSA) of $1.73 \mathrm{~m}^{2}$.

\section{Measurement of albuminuria :}

Preferred method for the detection of albuminuria in people with or without diabetes is urinary ACR in a first void specimen (morning specimen). A random spot urine for ACR is acceptable but positive test should be confirmed by first void sample.Urine ACR is more sensitive than protein:creatinine ratio (PCR) for detecting lower amounts of albuminuria but later is more reliable to measure higher protienuria such as nephrotic range protienuria. Albuminuria is said to be present if at least two out of three ACR results are positive. CKD is present if the albuminuria is persistent for at least three months. Dipstick for protein in the urine is now no longer recommended for this purpose as the sensitivity and specificity is not optimal. ACR is the ratio of urinary albumin $(\mathrm{mg} / \mathrm{L})$ to urinary creatinine $(\mathrm{mmol} / \mathrm{L})$. If urine creatinine is measured in $\mathrm{mg} / \mathrm{dl}$, reference values of ACR and PCR can be derived by dividing by $11.31^{6}$. 


\section{Stages of CKD :}

CKD is classified according to the GFR, albuminuria and the etiology. The cause of CKD is established according to the presence or absence of a systemic disease with potential kidney involvement or through observed or suspected pathological abnormalities(e.g. Stage 2 CKD with microalbuminuria secondary to diabetes). The GFR is graded in to G1- G5 where stage 3 has been sub divided in to $3 \mathrm{~A}$ and $3 \mathrm{~B}$. Albuminuria is classified as A1, A2 or A3 according to ACR in an isolated urine sample for values $<3,3-30$ or $>30 \mathrm{mg} / \mathrm{mmol}$, respectively ${ }^{7}$.

The Kidney Disease Outcomes Quality Initiative (KDOQI) stages of kidney disease are :

\begin{tabular}{|c|c|c|c|}
\hline Stage & GFR* & Description & Treatment stage \\
\hline 1 & 90+ & $\begin{array}{l}\text { Normal kidney function but } \\
\text { urine findings or structural } \\
\text { abnormalities or genetic trait } \\
\text { point to kidney disease }\end{array}$ & $\begin{array}{l}\text { Observation, control } \\
\text { of blood pressure. }\end{array}$ \\
\hline 2 & \begin{tabular}{|l|}
$60-89$ \\
\end{tabular} & $\begin{array}{l}\text { Mildly reduced kidney } \\
\text { function, and other findings } \\
\text { (as for stage 1) point to } \\
\text { kidney disease }\end{array}$ & $\begin{array}{l}\text { Observation, control } \\
\text { of blood pressure } \\
\text { and risk factors. }\end{array}$ \\
\hline $\begin{array}{l}3 \mathrm{~A} \\
3 \mathrm{~B} \\
\end{array}$ & $\begin{array}{l}45-59 \\
30-44\end{array}$ & $\begin{array}{l}\text { Moderately reduced kidney } \\
\text { function }\end{array}$ & $\begin{array}{l}\text { Observation, control } \\
\text { of blood pressure } \\
\text { and risk factors. }\end{array}$ \\
\hline 4 & $15-29$ & $\begin{array}{l}\text { Severely reduced kidney } \\
\text { function }\end{array}$ & $\begin{array}{l}\text { Planning for end } \\
\text { stage renal failure. }\end{array}$ \\
\hline 5 & $\begin{array}{l}<15 \text { or } \\
\text { on } \\
\text { dialysis }\end{array}$ & $\begin{array}{l}\text { Very severe, or end stage } \\
\text { kidney failure }\end{array}$ & $\begin{array}{l}\text { Treatment on } \\
\text { choices. }\end{array}$ \\
\hline
\end{tabular}

Following suffixes can also be added with above classification for better understanding-

\section{Suffixes :}

* $\mathbf{p}$ - the addition of $\mathbf{p}$ to a stage (e.g. 3Ap, 4p) means that there is significant proteinuria.

* $\mathbf{T}$ - the addition of $\mathbf{T}$ to a stage (e.g. 3AT) indicates that the patient has a renal transplant.

* D - the addition of $\mathbf{D}$ to stage 5 (e.g. 5D) indicates that the patient is on dialysis

\section{Assessment of CKD assessment :}

Normal renal progression rate is 0.7 $1 \mathrm{ml} / \mathrm{min} / 1.73 \mathrm{~m}^{2} /$ year $>40$ years of age. To assess renal progression, considerations are; albuminuria, baseline GFRand identification of renal progression factors.

CKD is considered as progressive when GFR is $>5 \mathrm{ml} / \mathrm{min} /$ year or $>10 \mathrm{ml} / \mathrm{min}$ in five years ${ }^{8}$. Progression must be defined on the basis of two aspects:

(I) Progression to a higher renal function deterioration category assessed by albuminuria such as category A1, $\mathrm{A} 2$ and $\mathrm{A} 3$.
(II) Percentage of change with respect to the baseline situation $(>25 \%$ deterioration in the GFR) or a more than $50 \%$ increase in the ACR.

The frequency of CKD patient monitoring:

Low-risk patients = annually.

Moderate-risk patients $=$ every six months.

High and very high-risk patients = three, four or more times a year. This regimen is valid for stable patients.

\section{Screening for CKD :}

Screening testing for CKD identification should not be universal. Individuals at increased risk of developing CKD such as DM, HBP, cardiovascular diseases, vasculitis or family history of kidney disease.Tests should include a urine ACR, serum creatinine to measure GFR and blood pressure measurement - "the Kidney Health Check".

Decreased GFR without kidney damage:

Individuals with GFR 60 to $89 \mathrm{~mL} / \mathrm{min} / 1.73 \mathrm{~m}^{2}$ without kidney damage are classified as "decreased GFR. They are usuallyinfants and older adults, and is usually considered to be "normal for age." In older age this is due to global glomerular sclerosis and cortical atrophy. This may be also found in vegetarian, unilateral nephrectomy, extracellular fluid volume depletion, heart failure and cirrhosis. Consequences of "decreased GFR"group have not been carefully studied but the Work Group concluded them as having no $\mathrm{CKD}^{7}$.

\section{Complications of CKD:}

The most common complications of CKD and their prevalence according to GFR grades are displayed in the Table below: $:^{9,10}$

\begin{tabular}{|c|c|c|c|c|c|}
\hline \multirow[t]{2}{*}{ Complication } & \multicolumn{5}{|c|}{ Glomerular filtration rate (m//min $\left./ 1.73 \mathrm{~m}^{2}\right)$} \\
\hline & $\geq 90$ & $60-89$ & 45.59 & 30.44 & $<30$ \\
\hline HBPP & 18.3 & 41.0 & 71.8 & 78.3 & 82.1 \\
\hline Anaemiat & 4.0 & 4.7 & 12.3 & 22.7 & 51.5 \\
\hline Hyperparathyoidism ${ }^{4}$ & 5.5 & 9.4 & 23.0 & 44.0 & 72.5 \\
\hline Hyperphosphatzemiaz & 72 & 7.4 & 9.2 & 9.3 & 23.0 \\
\hline Deficency of 25(OH) Vit D' & 14.1 & 9.1 & \multicolumn{2}{|c|}{10.7} & 27.2 \\
\hline Acidosis & 11.2 & 8.4 & 9.4 & 18.1 & 31.5 \\
\hline Hyposbuminzemiat & 1.0 & 13 & 28 & 9.0 & 7.5 \\
\hline
\end{tabular}

(HBP: high blood pressure. ${ }^{a}$ Data in percentages. ${ }^{b}$ Defined as systolic blood pressure $\geq 140 \mathrm{mmHg}$, diastolic blood pressure $\geq 90 \mathrm{mmHg}$ or use of antihypertensive medication. ${ }^{\mathrm{c} D e f i n e d}$ as levels of haemoglobin $<12 \mathrm{~g} / \mathrm{dl}$ in females and $<13.5 \mathrm{~g} / \mathrm{dl}$ in males. ${ }^{\mathrm{d} D e f i n e d}$ as intact parathyroid hormone $\geq 70 \mathrm{pg} / \mathrm{ml}$ $(\geq 7.4 \mathrm{pmol} / \mathrm{l})$. ${ }^{\mathrm{e}}$ Defined as serum phosphorus $\geq 4.5 \mathrm{mg} / \mathrm{dl}$ $(\geq 1.5 \mathrm{mmol} / 1)$. ${ }^{\mathrm{f}}$ Defined as serum levels $<15 \mathrm{ng} / \mathrm{ml}$ $(<37 \mathrm{nmol} / 1)$. ' Defined as serum bicarbonate $<21 \mathrm{mEq} / 1$. ${ }^{\mathrm{h}}$ Defined as serum albumin $<3.5 \mathrm{~g} / \mathrm{dl}$ ) 


\section{Management of CKD :}

The comprehensive management of cardio renal risk patients forms the basis of CKD management. It is necessary to rule out potentially reversible and exacerbation factors, such as obstructive uropathy, volume depletion, situations of haemodynamic instability or use of non-steroidal anti-inflammatory drugs (NSAID), cyclooxygenase 2 (COX-2) inhibitors, nephrotoxic antibiotics, radiocontrast agents or reninangiotensin system (RAS) blockers in certain haemodynamic conditions. Also the aim should be to identify progression factors, such as CKD etiology, age, sex, race, smoking habits, obesity, HBP, hyperglycemia, dyslipidaemia, previous cardiovascular disease and exposure to nephrotoxic agents.

\section{Treatment high blood pressure :}

In CKD patients, the objectives of anti-hypertensive treatment are three: to reduce BP, to reduce the risk of cardiovascular complications and to slow down CKD progression. In patients with an ACR $<3 \mathrm{mg} / \mathrm{mmol}$, the recommended BP control target is $(\leq 140 / 90 \mathrm{mmHg}$ (both diabetic and non-diabetic). If the ACR is ( $\geq 3 \mathrm{mg} / \mathrm{mmol}$, a stricter target is suggested, with BP $\leq 130 / 80 \mathrm{mmHg}$, both in patients with or without DM. The drugs of first choice are either ACEI or ARBs.The use of anti-hypertensive drug in combinations is recommended to achieve the control objectives. This combination must include a thiazide or loop diuretic depending on the severity of CKD. But concurrent use of ACEI and ARB is not recommended to avoid hypotension and acute deterioration of kidney function or hyperkalaemia.

Management of high blood pressure in elderly patients: A strict control of BP and the use of RAS blockers, which arekey in managing adult CKD patients, may not have the same benefits for very elderly patients, and may even have harmful effects.Antihypertensive treatment in this type of patient involves particular step therapy and monitoring of potential adverse effects, such as electrolyte imbalances, renal failure aggravation and orthostatic hypotension and their management should be particularly individualised ${ }^{11,12}$.

\section{Cardiovascular risk in CKD:}

CKD patients, particularly in grades 3 a to 5, have an increased cardiovascular risk corresponding to HBP or DM.The risk of having a major cardiovascular complication increases from $43 \%$ in CKD grade 3 a to $>300 \%$ in grades $4-5$ with respect to individuals without $\mathrm{CKD}^{13}$. In fact $\mathrm{CKD}$ patients have a greater risk of cardiovascular mortality than requiring renal replacement therapy via dialysis or renal transplantation.
It is also advised for patients of CKD with acute coronary events or heart failure to receive the same level of diagnostic and therapeutic intervention as those without CKD. It should be keep in mind that some diagnostic tests, such as those of troponins or BNP/NTproBNP (B-type natriuretic peptide/N-terminalproBNP), should be interpreted with caution in $\mathrm{CKD}$ patients, particularly those with an eGFR $<60 \mathrm{ml} / \mathrm{min} / 1.73 \mathrm{~m}^{2}$, since the standard reference values may not have the same significance as in patients without CKD.

\section{Treatment of Anaemia:}

In CKD patients, anaemia is defined as haemoglobin $\mathrm{Hb}$ concentration in blood is two standard deviations below the mean $\mathrm{Hb}$ concentration of the general population, corrected for age and $\operatorname{sex}^{14}$. Anaemia associated with CKD is usually normocytic and normochromic in origin and is related to a decrease in erythropoietin production by peritubular cells, low bone marrow response, an increased production of hepcidin and a decrease in the availability of iron for erythropoiesis. The treatment of anaemia in CKD demands when $\mathrm{Hb}$ is $<11 \mathrm{~g} / \mathrm{dl}$ in premenopausal females and prepubertal patients and $<12 \mathrm{~g} / \mathrm{dl}$ in adult males and postmenopausal females. The key aspects to correct anaemia include: 1) ruling out secondary causes, mainly iron deficiency, 2) giving patients iron supplements in cases of deficiency, 3) using ESA with target haemoglobin not exceeding $11.5 \mathrm{~g} / \mathrm{dl}$ and 4 ) blood transfusion in special situations. Basic tests include a complete blood count, reticulocytes count, serum iron, serum ferritin, the transferrin saturation index (TSI), serum vitamin B12 and folate level. In anaemia associated with CKD iron supplements are given if TSI is $\leq 30 \%$ and serum ferritin is $\leq 200 \mathrm{ng} / \mathrm{ml}$. Oral iron administration regimen in adults: $200 \mathrm{mg} /$ day and in children: $2-3 \mathrm{mg} / \mathrm{kg} /$ day. In pre-dialysis, home dialysis and peritoneal dialysis (PD) adults who do not achieve adequate iron reserves with $\mathrm{Fe}$ by the oral route, a $100 \mathrm{mg}$ infusion of $\mathrm{Fe}$ dextran or 500-1000mg of intravenous $\mathrm{Fe}$ carboxymaltose should be administered.It is unlikely for Haemodialysis (HD) patients to achieve the target with oral $\mathrm{Fe}$, and as such, intravenous iron will be required. In patients not treated with ESA, the target must be TSI $\geq 20 \%$ and Ferritin $\geq 100 \mathrm{ng} / \mathrm{ml}$. Target $\mathrm{Hb}$ is between 10 and $12 \mathrm{~g} / \mathrm{dl}$. Patients must be monitored every 3-6 months. The test must be carried out 15 days after the last dose of intravenous Fe.

Treatment of anaemia with erythropoiesis-stimulating agents (ESA) :

Before staring ESA considerations are (a) Addressing all correctable causes of anemia like iron deficiency and inflammatory conditions i.e.; rheumatoid arthritis, 
systemic lupus erythematosus (SLE) or any other connective disease. (b) Balancing between potential benefits of reducing blood transfusions and anemiarelated symptoms by ESA against the risks of stroke, thrombosis and hypertension aggravation in individual. (c) Be cautious, in patients with active malignancy, a history of stroke. (d) ESA therapy is not initiated in CKD non-dialysis (ND) patients with $\mathrm{Hb}$ concentration $10.0 \mathrm{~g} / \mathrm{dl}$ or more. (e) ESA therapy is indicated in CKD $\mathrm{ND}$ patients with $\mathrm{Hb}$ concentration below $10.0 \mathrm{~g} / \mathrm{dl}$ and therapy be individualized based on the rate of fall of $\mathrm{Hb}$ concentration, prior response to iron therapy, the risk of needing a transfusion, the risks related to ESA therapy and the presence of symptoms attributable to anemia. (f) ESA is not be used to intentionally increase the $\mathrm{Hb}$ concentration above $13 \mathrm{~g} / \mathrm{dl}(130 \mathrm{~g} / \mathrm{l})$. (g) In patients with ESA without intravenous $\mathrm{Fe}$, the monitoring should be monthly until $\mathrm{Hb}$ has stabilized between 10 and $12 \mathrm{~g} / \mathrm{dl}$ which is the target. Evaluate iron status (TSI and ferritin) at least every 3 months during ESA therapy, including the decision to start or continue iron therapy. Subcutaneous administration is indicated in HD, Peritoneal dialysis (PD) and home dialysis patient. The intraperitoneal route or intravenous route is needed in cases of higher doses (volume) or recurrent ecchymosis at the site of injection. Transfusions in CKD patients needed in patients with functional anaemia and who are resistant to ESA with chronic blood loss.

\section{Treatment of bone metabolism disorders :}

Treatment objectives are-

* Avoid hyperphosphataemia.

* Maintain normal levels of calcium, phosphorus and parathormone (PTH).

* Avoid the onset and progression of secondary hyperparathyroidism.

Hyperphosphataemia is corrected by dietary restriction of eggs, milk, cheese and high protein; and by phosphate binders like calcium carbonate, calcium acetate or its combination with magnesium, sevelamer and lanthanum carbonate. Aluminium compounds are excellent binders, but are not recommended over long periods which may induce aluminium intoxication. Vitamin D deficiency is corrected by Cholecalciferol (D3) $(800 \mathrm{IU}=12$ drops, 50 000IU $=25 \mathrm{ml})$ or Calcifediol (25-OH-vitamin D):0.266mg (calcifediol 16 $000 \mathrm{IU})$. Secondary hyperparathyroidism is treated by Calcitriol and vitamin D analogues: renal hydroxylation is not required to obtain the active form. These include $\left\{\right.$ calcitriol; $\left.1,25-(\mathrm{OH})_{2}-\mathrm{D}_{3}\right\}$ and $\{$ alfacalcidol; $1 \alpha-(\mathrm{OH})-$ $\left.\mathrm{D}_{3}\right\}$. Alfacalcidol requires activation in the liver. The condition can also be corrected by selective vitamin D receptor activators (paricalcitol) where there is a lower likelihood of hypercalcaemia, hyperphosphataemia, and vascular calcifications. Calcimimetics (cinacalcet) is indicated in the treatment of hyperparathyroidism in dialysis and tertiary hyperparathyroidism when parathyroidectomy is not possible or unsuccessful.

\section{Management of Acidosis :}

Acidosis is corrected byoral bicarbonate supplements in patients with bicarbonate concentrations $<22 \mathrm{mEq} / 1$, if it is not contraindicated.

\section{Management of dyslipidaemia :}

Control of dyslipidaemia in CKD reduce not only atherosclerotic events but also slow the progression of the disease ${ }^{6}$. Combination of simvastatin $10 \mathrm{mg}$ and ezetimibe $20 \mathrm{mg}$ daily in CKD patients has shown reduced atherosclerotic events both in non-dialysis (17\%) and dialysis individuals ${ }^{15}$. Recently the KDIGO guidelines recommends for treating dyslipidaemia in CKD with statins for all adults $>50$ years of age, independently of low density lipoprotien (LDL) cholesterol levels. Lifestyle modifications are done by taking $30 \%$ or less of the total calories from fatty foods and less than $10 \%$ be saturated fats. Cholesterol is not more than $300 \mathrm{mg} /$ day. The drugs of choice are fluvastatin, atorvastatin, pitavastatin and ezetimibe. It is not necessary to adjust statin dose, except in very advanced stages of CKD. Due to lack of evidence on the cardiovascular benefit of hypertriglyceridaemia treatment, correction of this is not recommended. The therapeutic goal is LDL cholesterol $<70 \mathrm{mg} / \mathrm{dl}$ or a $50 \%$ reduction if the previous objective is not achievable.

\section{Nutritional and metabolic control :}

Reduce salt intake to between 4 and 6 gm per day. High dietary protein intake in CKD patients results in an accumulation of uraemic toxins, but insufficient intake may lead to malnutrition. So reduce protein intake to $0.8 \mathrm{~g} / \mathrm{kg} /$ day in adults with an estimated GFR $<30 \mathrm{ml} / \mathrm{min} / 1.73 \mathrm{~m}^{2}$ (CKD grades $4-5$ ) without evidence of malnutrition. But patients on haemodialysis (HD), protein intake may be increased by up to $1.2 \mathrm{~g} / \mathrm{kg}$ in order to achieve an adequate protein balance, avoid calorie-energy exhaustion and attain an adequate nutritional status. In diabetic patients, a glycated haemoglobin $\left(\mathrm{HbA}_{1 \mathrm{C}}\right)$ target $<7 \%$ is recommended, except in frail patients at risk of hypoglycaemia or with major comorbidities that may reduce life expectancy, for whom the $\mathrm{HbA} 1 \mathrm{C}$ target is between $7.5 \%$ and $8 \%$. In very elderly and frail patients, a more relaxed $\mathrm{HbA}_{1 \mathrm{C}}$ target of $<8.5 \%$ may be considered. Inpatients with CKD and symptomatic hyperuricaemia (uric acid lithiasis or gout),uric acid levels of less than $7 \mathrm{mg} / \mathrm{dl}$ should be achieved ${ }^{16}$ by xanthenes oxidase inhibitors. Moderate alcohol intake, (12 to $14 \mathrm{~g}$ of alcohol, around $300 \mathrm{cc}$ of beer or $150 \mathrm{cc}$ of wine) is not considered as harmful but calories present in alcohol, the quantity of liquid, sugar, potassium, phosphorus and sodium content must be considered and counted. 
Obesity :

Reduction of body weight and less intake of fat may decrease the risk of CKD. Treatment of obesity in CKD patients must be non-pharmacological and consist of physical exercise and a low-calorie diet. The use of drugs to reduce appetite like orlistat is not indicated in CKD patients.

\section{Physical exercise :}

As a general rule, it is recommended to carry out 30-60 minutes of moderate exercise 4 to 7 days a week. In CKD cases the exercise must be adapted to the physical ability of each patient.

\section{Smoking :}

Smoking is directly involved in kidney disease progression. All patients are encouraged to quit smoking and if needed cognitive-behavioral techniques, pharmacological treatment like nicotine replacement therapy (patches, chewing gum, sweets), as well as their combination with lower doses of bupropion $(150 \mathrm{mg} / 24 \mathrm{~h})$ are recommended.

\section{Safety Aspects in CKD Patients :}

CKD patients are vulnerable to certain very common situations in healthcare and at risk of sudden deterioration of kidney function further or acute renal failure (ARF) particularly in cases of intercurrent diseases and situations of hospitalization or any diagnostic or therapeutic procedure.

\section{Use of drugs in kidney disease patients :}

The main recommendations about the use of drugs in CKD patients are: (1) use GFR for drug dose calculation; (2) temporarily discontinue potentially nephrotoxic drugs or drug that is eliminated via the kidneys, when eGFR $<60 \mathrm{ml} / \mathrm{min} / 1.73 \mathrm{~m}^{2}$ in severe intercurrent disease, mainly ACE inhibitors, ARBs, aldosterone antagonists, diuretics, NSAIDs, metformin, lithium and digoxin; (3) don't use herbal medicine; (4) don't use metformin in eGFR $<45 \mathrm{ml} / \mathrm{min} / 1.73 \mathrm{~m}^{2}$; and (5) monitor kidney function, electrolytes and drug levels in patients who receive potentially nephrotoxic drugs, mainly aminoglycoside antibiotics, lithium, calcineurin inhibitors and digoxin.

\section{Use of radiological contrasts :}

In patients with a GFR $<60 \mathrm{ml} / \mathrm{min} / 1.73 \mathrm{~m} 2$, use low osmolarity iodine agents with minimum possible dose of the agent. Discontinue potentially nephrotoxic drugs beforehand, particularly metformin, ensure adequate hydration with saline before, during and after the procedure and monitor the GFR 48-96 hours after the latter. Avoid the use of gadolinium-based contrasts in patients with an eGFR $<15 \mathrm{ml} / \mathrm{min} / 1.73 \mathrm{~m}^{2}$, except when there is no alternative. In patients with an eGFR $<30 \mathrm{ml} / \mathrm{min} / 1.73 \mathrm{~m}^{2}$, it is advised to avoid the use of gadodiamide and use other preparations, such as gadoteridol, gadobutrol o gadoterate. It is recommended for a dialysis session immediately after the procedure and after 24 hours if possible. It is recommended not to use oral preparations with phosphates for intestinal preparation in patients with an eGFR $<60 \mathrm{ml} / \mathrm{min} / 1.73 \mathrm{~m}^{2}$. If the phosphate preparations are inevitably used dehydration must be avoided.

\section{Hyperglycaemia management in CKD :}

Glycatedhaemoglobin $\mathrm{A}_{1 \mathrm{C}}\left(\mathrm{HbA}_{1 \mathrm{C}}\right)$ is the reference parameter for assessing metabolic control in patients CKD with DM. Target of control in patients with shortterm DM and without a decrease in life expectancy, is $\mathrm{HbA}_{1 \mathrm{C}}<7(<53 \mathrm{mmol} / \mathrm{mol})$ and for patients with longterm DM with a previous history of poor glycaemic control or with a condition that decreases life expectancy, the control target must be individualized avoiding hypoglycaemia. Optimal $\mathrm{HbA}_{1 \mathrm{C}}$ level for dialysis patients is not yet determined. Sulfonylurea's (SU) are not the first drug of choice in renal failure. Glibenclamide and glimepiride, even in low doses, are not recommended in CKD. Glipizide is the only SU that could be used in CKD up to but $\mathrm{CCr}>30 \mathrm{ml} / \mathrm{m}$. Repaglinide in a low dose $(0.5 \mathrm{mg})$ may be given. Metformin is not recommended with an eGFR $<60 \mathrm{ml} / \mathrm{min}$. Both acarbose and miglitol are not recommended in CKD. Glitazones may be given with the risk of edema, heart failure and osteoporosis and contraindicated in those on dialysis. Gliptins (Sitagliptin, vildagliptin and saxagliptin) can be prescribed without dose adjustment up to an eGFR greater than $50 \mathrm{ml} / \mathrm{min} / 1.73 \mathrm{~m}^{2}$ beyond which adjustment is a must. Linagliptin does not require dose adjustment in any stage of CKD. Regarding Glucagon-like peptide1 analogues Liraglutide is only advocated in patients with an eGFR $>60 \mathrm{ml} / \mathrm{min} / 1.73 \mathrm{~m}^{2}$ although experience with liraglutide and exenatide in this field is very limited.

\section{Insulin use in CKD :}

Insulin requirements are very variable and as such, individualization of treatment is essential. Followings are the rules for insulin use in CKD patients.

$* \mathrm{CCr}>50$ : does not require a dose adjustment.

* CCr 50-10: will require a 75\% reduction of the previous insulin dose.

$* \mathrm{CCr}<10$ : will require a $50 \%$ reduction of the previous insulin dose. 
The need for insulin is decreased because of less caloric intake in uremic patients. With the institution of hemodialysis the need for insulin changes because the insulin sensitivity and liver metabolism improve. Long acting basal insulin like insulin glargin does not produce hypoglycemia in CKD.

\section{Criteria for Referral to Nephrology :}

This depends on the stage of CKD (i.e.; on eGFR), the speed of renal failure progression, the degree of albuminuria, associated comorbidities and the patient's functional status ${ }^{17}$.

According to glomerular filtration rate :

- All patients with an eGFR $<30 \mathrm{ml} / \mathrm{min} / 1.73 \mathrm{~m}^{2}$, except patients $>80$ years of age without renal progression.

- Patients $>80$ years of age and with an eGFR $<20 \mathrm{ml} / \mathrm{min} / 1.73 \mathrm{~m}^{2}$, if their general condition allows them for specific treatment.

- Age $<40$ yrs irrespective of eGFR 6 .

According to albuminuria :

ACR $>70 \mathrm{mg} / \mathrm{mmol}$ or $\mathrm{PCR}>100 \mathrm{mg} / \mathrm{mmol}^{6}$.

\section{Other reasons :}

- Acute or rapid deterioration of renal function characterized by (a) $>25 \%$ decrease in the eGFR in less than a month or (b) fall in eGFR $>5 \mathrm{ml} / \mathrm{min} / 1.73 \mathrm{~m}^{2} /$ year or $>10 \mathrm{ml} / \mathrm{min} / 1.73 \mathrm{~m}^{2}$ in 5 years.

- CKD and HBP refractory to treatment $(>140 / 90 \mathrm{mmHg})$ with three drugs at full dose, one of them being a diuretic.

- Abnormalities in potassium $(>5.5 \mathrm{mEq} / 1$ or $<3.5 \mathrm{mEq} / 1$ without the patient receiving diuretics).

- Anaemia-haemoglobin $[\mathrm{Hb}]<10.5 \mathrm{~g} / \mathrm{dl}$ with $\mathrm{CKD}$ in spite of correcting iron deficiency (TSI $>20 \%$ and ferritin $>100$ ).

- Non-urological haematuria associated with proteinuria.

\section{Conclusion :}

Patients with CKD are more likely to die of cardiovascular disease than to require dialysis. Therefore, reduction of morbidity and mortality in CKD requires good management of cardiovascular disease risk factors. Selection of patients for ESA should be done by specialist, not by primary health care provider to avoid thrombotic events and intentionally to raise the $\mathrm{Hb}$ level. Appropriate referral to nephrologist is mandatory, to minimise the burden to limited resources in nephrology units specially in Bangladesh context and also to avoid non-scheduled dialysis to them who needs RRT.

\section{References :}

1. Improving Global Outcomes (KDIGO) CKD Work Group. KDIGO 2012 clinical practice guideline for the evaluation and management of chronic kidney disease.Kidney Inter Suppl. 2013;3:1-150.

2. National Kidney Foundation. K/DOQI clinical practice guidelines for chronic kidney disease: Evaluation, classification, and stratification. Am J Kidney Dis 2002;39(2 Suppl 1):S1-266.

3. Levey AS, Coresh J, Balk E, Kausz AT, Levin A, Steffes MW, et al. National Kidney Foundation practice guidelines for chronic kidney disease: evaluation, classification, and stratification. Ann Intern Med 2003;139:137-47.

4. Levey AS, Stevens LA, Schmid CH, Zhang YL, Castro AF, Feldman HI, et al. CKD-EPI (Chronic Kidney Disease Epidemiology Collaboration). A new equation to estimate glomerular filtration rate. Ann Intern Med 2009;150:604-12.

5. Alberto MC, Jose L, Gorriz T,Jordi BS, Julian SDM, Jesus C, Javier $\mathrm{E}$, et al. Consensus document for the detection and management of chronic kidney disease. Nefrologia 2014;34(2):243-262.

6. Goddard J,Turner AN. Kidney and urinary tract disease. In: Walker BR, Colledge NR, Ralston SH, Penman ID, editors. Davidson's principles \& practice of medicine. 22nd ed. Churchill Livingstone: Elsevier; 2014:p476-88.

7. Manuel G, Rafael S, Roberto A, Gema FF, Josep MG, Marian G, et al. Spanish Society of Nephrology document on KDIGO guidelines for the assessment and treatment of chronic kidney disease.Nefrologia 2014;34(3):302-16.

8. Otero A, de Francisco A, Gayoso P, García F. The EPIRCE Study Group. Prevalence of chronic renal disease in Spain: results of the EPIRCE study. Nefrologia 2010;30(1):78-86.

9. Levin A, Bakris GL, Molitch M, Smulders M, Tian J, Williams LA, et al. Prevalence of abnormal serum vitamin D, PTH, calcium, and phosphorus in patients with chronic kidney disease: results of the study to evaluate early kidney disease. Kidney Int 2007;71:31-8.

10. Inker LA, Coresh J, Levey AS, Tonelli M, Muntner P. Estimated GFR, albuminuria, and complications of chronic kidney disease. J Am SocNephrol 2011;22:2322-31.

11. Fischer MJ, O'Hare AM. Epidemiology of hypertension in the elderly with chronic kidney disease.Adv Chronic Kidney Dis 2010;17:329-40.

12. Turgut F, Balogun RA, Abdel-Rahman EM. Renin-angiotensinaldosterone system blockade effects on the kidney in the elderly: benefits and limitations. Clin J Am SocNephrol 2010;5:1330-9.

13. Hallan SI, Dahl K, Oien CM, Grootendorst DC, Aasberg A, Holmen J, et al. Screening strategies for chronic kidney disease in the general population: follow-up of cross sectional health survey. BMJ 2006;333:1047.

14. Locatelli F, Aljama P, Bárány P, Canaud B, Carrera F, Eckardt $\mathrm{KU}$, et al. European Best Practice Guidelines Working Group. Revised European best practice guidelines for the management of anaemia in patients with chronic renal failure. Nephrol Dial Transplant 2004;19Suppl 2:ii1-47.

15. SHARP Collaborative Group. Study of Heart and Renal Protection (SHARP): randomized trial to assess the effects of lowering low-density lipoprotein cholesterol among 9,438 patients with chronic kidney disease. Am Heart J 2010;160:785-94.

16. Johnson R, Nakagawa T, Jalal D, Sanchez-Lozada LG, Kang DH, Ritz E, et al. Uric acid and chronic kidney disease. Which is chasing with? Nephrol Dial Transplant 2013;28:2221-8.

17. Navaneethan SD, Aloudat S, Singh S. A systematic review of patient and health system characteristics associated with late referral in chronic kidney disease. BMC Nephrology 2008;9:3. 